\title{
Os cárceres da Guanabara através do jornal Ultima Hora (1960-1961)
}

\author{
The prisons of Guanabara through the newspaper Ultima Hora (1960-1961) \\ Mariana Dias Antonio \\ https://orcid.org/0000-0002-4596-2399 \\ Universidade Federal do Paraná
}

Resumo: O presente artigo busca analisar quatro séries de reportagens sobre alguns presídios do estado da Guanabara publicadas pelo jornal carioca Ultima Hora, entre 1960 e 1961. Os anos escolhidos compreendem a criação de um novo estado, a eleição de Carlos Lacerda como governador, a reorganização dos serviços de segurança pública, a renúncia de um presidente da República e tentativas de barrar sua sucessão legal, resultando em diversos ruídos possíveis do campo político sobre o campo jornalístico. Não obstante, deve-se pontuar que Carlos Lacerda já apresentava um longo histórico de conflitos com o jornal Ultima Hora, levando a uma ferrenha oposição do jornal ao longo de sua gestão. Cientes desse cenário e dos diversos ruídos possíveis, nossa análise prioriza as formas e alterações de enquadramento jornalístico sobre os presídios, detentos, agentes prisionais e policiais, bem como o Poder Público de forma ampla. A análise revela, ao mesmo tempo, mudanças nas representações coletivas sobre esses assuntos e permanências históricas de arbitrariedades policiais, usualmente associadas ao contexto autoritário posterior a 1964, bem como as denúncias que eclodiriam em 1963 quanto ao extermínio de moradores de rua. Palavras-chave: Ultima Hora. Guanabara. Violência policial. Sistema prisional. Jornalismo.

\begin{abstract}
This paper aims to analyze four news report series on some prisons in the state of Guanabara published by the newspaper Ultima Hora, from Rio de Janeiro, between 1960 and 1961. The chosen years comprehend the creation of a new state, the election of Carlos Lacerda as its governor, the reorganization of public security services, the resignation of a president of the Republic and attempts to block his legal succession, resulting in several possible noises from the political field over the journalistic field. Nevertheless, it should be noted that Carlos Lacerda had a long history of conflicts with the newspaper Ultima Hora, leading to a fierce opposition from the newspaper throughout his term. Aware of this scenario and of the various possible noises, our analysis prioritizes the forms and changes in the journalistic framing about prisons, detainees, prison and police agents, as well as the Government in a broad way. The analysis reveals, at the same time, changes in the collective representations about these subjects and historical permanence of police arbitrariness, usually associated with the authoritarian context after 1964, as well as the denunciations that would break out in 1963 regarding the extermination of homeless people.
\end{abstract}

Keywords: Ultima Hora. Guanabara. Police violence. Prison system. Journalism.

As fontes de imprensa têm ganhado atenção crescente em estudos sobre violência policial e um exemplo repousa no recente interesse da academia acerca do Esquadrão da Morte ${ }^{1}$ (ANTONIO, 2017; LEITÃO, 2017; MELLO NETO, 2014; OLIVEIRA, 2016). Tal interesse, aliado à adoção mais ampla e frequente dessas fontes, desloca certa percepção social da violência institucional como algo mais característico de contextos autoritários, como a ditadura varguista ou

Esta obra está licenciada sob uma Creative Commons - Atribuição 4.0 Internacional

\footnotetext{
1 O Esquadrão da Morte pode ser descrito, grosso modo, como uma categoria genérica que contempla diversos grupos organizados ou de oportunidade em diferentes momentos e contextos. As narrativas tratam basicamente de grupos que eliminam bandidos através de um modus operandi específico: tiros de diversos calibres, cartazes sobre as vítimas, sinais de enforcamento e manietamento, corpos abandonados em locais ermos etc. Como exemplos, elencamos apenas trabalhos que priorizam diários cariocas, mas a produção acerca do Esquadrão da Morte também teve avanços recentes a partir de semanários e veículos de imprensa de outras localidades.
} 
o regime militar, e evidencia permanências que resistem tanto a períodos autoritários quanto democráticos.

O crescimento do interesse por uma fonte implica no aumento dos cuidados com a mesma e as diversas influências, reais ou potenciais, sobre sua produção devem ser levadas em conta. Conforme Jacques Le Goff (2006, p. 535-536), "[o] documento não é qualquer coisa que fica por conta do passado, é um produto da sociedade que o fabricou segundo as relações de força que aí detinham o poder". Cientes de certas permanências na violência institucional, buscamos analisar eventuais influências de um contexto político polarizado e turbulento sobre o enquadramento jornalístico dessas formas de violência. Nosso interesse repousa nas representações de alguns cárceres da Guanabara a partir de séries policiais publicadas no jornal Ultima Hora em 1960 e 1961.

O Ultima Hora foi fundado pelo jornalista Samuel Wainer, sediado na cidade do Rio de Janeiro (posteriormente fundando diversas sucursais pelo Brasil) e com circulação diária (exceto aos domingos). Circulou pela primeira vez em 12 de junho de 1951 trazendo um jornalismo voltado às camadas populares com amplo uso de imagens e do sensacionalismo. Uma vez que o termo "sensacionalismo" traz consigo conotações negativas, Marialva Barbosa (2007) prefere abordar os jornais populares através do termo "jornalismo de sensações", marcado por um apelo afetivo ao leitor, ao seu imaginário e quebra de uma suposta normalidade.

O jornalismo popular - mas que preferimos qualificar como de sensações - assume a partir dos anos 1950, gradativamente, nova configuração no cenário midiático do Rio de Janeiro. Continua apelando a conteúdos e formatos narrativos que fazem parte do universo do público desde o final do século XIX, mas constrói naquele momento uma ruptura: a inclusão de outros temas do cotidiano dos leitores que têm apelo de natureza política (BARBOSA, 2007, p. 212).

No caso do Ultima Hora, o recurso ao sensacional figurava especialmente na seção policial, ocorrendo também em outros espaços do jornal, sobretudo quando as notícias policiais esbarravam em questões políticas mais amplas ou dialogavam com o cenário político vigente.

Sua fundação decorre do apoio político de Getúlio Vargas, presidente da República recémempossado em 1951, bem como do financiamento de empresários e banqueiros. Sendo uma espécie de plataforma de Vargas e seu partido (PTB - Partido Trabalhista Brasileiro), o jornal tinha entre seus opositores o jornalista e político Carlos Lacerda. Alguns episódios, ao longo da década de 1950, marcam os conflitos entre Wainer e Lacerda, como a instauração de uma Comissão Parlamentar de Inquérito (CPI), em 1953, para investigar empréstimos ilícitos a veículos de imprensa, com destaque para o Ultima Hora (LAURENZA, 1998; MENDONÇA, 2002; WAINER, 1988).

Em 22 de maio de 1954, o repórter Nestor Moreira, do jornal A Noite, morreu em decorrência de espancamento por policiais em Copacabana ${ }^{2}$. A fatalidade causou grande comoção na imprensa brasileira e rendeu a Lacerda uma alcunha que ele carregaria até o fim de sua carreira. Wainer solicitou a Lanfranco Vaselli (cartunista do Ultima Hora) que desenhasse uma charge de Lacerda para atacar sua suposta morbidez no funeral de Moreira, e o resultado foi Lacerda metamorfoseado num corvo, uma das charges mais famosas da história do Ultima Hora e da carreira de Lanfranco (ROSE, 2001; WAINER, 1988). A primeira charge do corvo foi publicada em 25 de maio de 1954.

Esse espancamento, entretanto, não resultaria apenas numa intensificação dos conflitos entre Wainer e Lacerda. Pouco após o episódio, o jornalista Edmar Morel e o fotógrafo Jader Neves, ambos do Ultima Hora, foram autorizados pelo ministro da Justiça, Tancredo Neves, a visitar os

\footnotetext{
2 O episódio que culminou na morte de Nestor Moreira teve início em 12 de maio de 1954. Após um desentendimento sobre o valor de uma corrida de táxi, Moreira foi conduzido pelo policial Celito Ferreira Quitete até o $2^{\circ}$ DP de Copacabana para resolver o problema. Após ser revistado, o repórter reclamou sobre a falta de mil cruzeiros em sua carteira ao policial Paulo Ribeiro Peixoto, vulgo "Coice de Mula", que o espancou perante o taxista e outros dois guardas. Antes de vir a óbito, Moreira agonizou por dez dias em um leito do Hospital Miguel Couto, em função das múltiplas lesões sofridas (SANDER, 2010).
} 
cárceres da polícia e denunciar as más condições de infraestrutura carcerária e o despreparo das autoridades no trato com os detentos. Segundo José Amaral Argolo (2008) e Robert Sterling Rose (2001), o repórter fora desligado do jornal e a série de reportagens repentinamente cessada. Entretanto, buscas pelo nome do jornalista no repositório da Hemeroteca Digital da Biblioteca Nacional remetem a diversas reportagens assinadas por Morel após o incidente. Depreendemos, assim, que apenas aquela série de reportagens foi interrompida, mas não a atuação profissional de Morel no Ultima Hora. Frederico de Oliveira (2016) destaca os momentos posteriores à morte de Nestor Moreira como um período de crescente sensacionalismo e denuncismo da imprensa carioca contra a polícia, consolidando e difundindo narrativas sobre violência e criminalidade que podem ter contribuído para a criação do fenômeno "Esquadrão da Morte" em fins da década de 1950.

Outros casos sobre abusos policiais e maus-tratos a detentos foram denunciados nos anos seguintes por diversos jornais. O Ultima Hora acompanha esse movimento, e o início da década de 1960 é de particular interesse por apresentar várias séries de reportagens denunciativas publicadas num curto espaço de tempo. Não obstante, Lacerda foi empossado governador do recém-criado estado da Guanabara em 5 de dezembro de $1960^{3}$. Nesse contexto, as séries em questão nos permitem explorar o uso do sensacionalismo no jornalismo policial enquanto buscamos por eventuais influências políticas sobre as formas de enquadramento jornalístico. Consideramos "enquadramento" o modo com que um veículo de comunicação constrói, organiza e apresenta seu ponto de vista sobre o conteúdo que tornará público (MCCOMBS, 2009).

Analisamos quatro séries de reportagens publicadas entre agosto de 1960 e novembro de 1961. A primeira série conta com quatro reportagens assinadas por Amado Ribeiro entre $1^{\circ}$ e 4 de agosto de 1960; a segunda conta com oito reportagens do mesmo repórter entre 22 e 30 de setembro de 1961; a terceira, também de Amado Ribeiro, conta com cinco reportagens publicadas entre 5 e 10 de outubro de 1961; e a quarta conta com cinco reportagens publicadas entre 3 e 8 de novembro de 1961 e assinadas pelo repórter Silvio Paixão. As séries foram consultadas junto ao repositório on-line da Hemeroteca Digital da Biblioteca Nacional. Através delas buscamos compreender como o jornal construiu, em suas relações comunicacionais com o público leitor da Guanabara, certas representações dos detentos, do Estado, dos agentes policiais e carcerários, bem como uma suposta representação do detento perante esses agentes e, sobretudo, se o contexto político cambiante pode explicar mudanças nessas representações e nas formas de enquadramento jornalístico. Tomamos o jornal como veículo de difusão cultural que nos auxiliará na compreensão de determinados discursos sobre indivíduos, papéis e instituições num imaginário social, temporal e territorialmente circunscrito.

\section{Os Presídios da llha Grande}

A série de quatro reportagens publicadas nos dias $1^{\circ}, 2,3$ e 4 de agosto de 1960 , realizadas pelo repórter Amado Ribeiro, denuncia as condições dos presídios da llha Grande enfatizando as más situações de infraestrutura e higiene. Aos detentos atribuem-se diversos termos pejorativos como: "feras humanas", "feras enjauladas", "criminosos sanguinários", "sombrios inquilinos", "loucos perigosos", "tuberculosos", "morféticos", "sifilíticos", "aleijados", "encarcerados", "monstros", "loucos", "companheiros de desgraça", "criminosos da pior espécie, tidos como irrecuperáveis", "componentes daquela sombria comunidade", "punhado de desgraçados", "feios", "analfabetos", "portadores de doenças contagiosas, de má aparência - pretos, na maioria”, "os sem profissão", "presos", "elementos", "invertido sexual", "anormais que, propositadamente, assumem trejeitos femininos", "pervertidos, elementos tidos como incorrigíveis", "malandros das favelas cariocas",

\footnotetext{
${ }^{3}$ O estado da Guanabara passa a existir com a Lei $n^{\circ} 3.752$ de 14 de abril de 1960, compreendendo os mesmos limites geográficos da cidade do Rio de Janeiro, antiga capital federal brasileira e ex-sede do governo estadual do Rio de Janeiro. A extinção do estado da Guanabara e sua fusão com o estado do Rio de Janeiro ocorreu em 1975, com a Lei Complementar $\mathrm{n}^{\circ} 20$ de $1^{\circ}$ de julho de 1974. A fusão se deu em 15 de março de 1975.
} 
"indivíduos monstruosos", "bandidos", "amotinados", entre outros. Sobre o presídio recaem termos como: "estreitos cubículos", "celas infectas", "inferno de loucos e monstros", "cidade dos mortosvivos", "Ilha dos Esquecidos", entre outros. ${ }^{4}$

$\mathrm{Na}$ época das reportagens, a Ilha Grande possuía dois sistemas prisionais: a Colônia Penal Cândido Mendes (CPCM), situada na Vila do Abraão e a Colônia Agrícola do Estado da Guanabara (CAEG), na Vila Dois Rios, que se vinculavam administrativamente à Guanabara, apesar de ocuparem território fluminense (SANTOS, 2018). Há um trânsito constante entre as duas colônias ao longo da série, mas sem grandes distinções entre os juízos emitidos, adjetivos empregados e formas de enquadramento jornalístico.

O propósito do repórter Amado Ribeiro e do fotógrafo José Gomes seria fornecer uma descrição detalhada dos detentos, em sua maioria doentes (mentais e físicos) e criminosos "irrecuperáveis". Com base nas reportagens, essas categorias de detentos eram destinados à llha Grande "[...] porque não podem permanecer na Penitenciária Central, espécie de cartão de visitas do sistema penitenciário, que deve aparentar apenas, para os visitantes, um ar de tranqüilidade, limpeza e disciplina"

Não são apresentadas denúncias de tortura, espancamento ou assassinato de detentos por policiais, mas o relato dos próprios detentos e policiais sobre o cotidiano na llha Grande. O sensacionalismo é presente em toda a série, havendo um excesso de desenvolvimento textual em casos pontuais por meio da redundância, dispondo ao leitor informações esparsas e sem muita densidade de conteúdo. Um dos exemplos de sensacionalismo é evidente ao narrar que "[p]ela primeira vez na história sinistra do célebre presídio de llha Grande [...] dois repórteres conseguiram vasculhar todos os seus segredos [...]" $]^{\prime \prime}$, ignorando-se o longo histórico dos sistemas prisionais da Ilha Grande e reportagens investigativas e denunciativas anteriores, por outros periódicos e jornalistas ${ }^{7}$.

A série é finalizada com um apelo para solucionar questões de abastecimento local, sendo urgente "[...] a liberação das verbas de alimentação para os presos. Do contrário, as despensas das Colônias estarão vazias até outubro", o que forçaria uma intervenção das forças armadas "[...] para conter os 1.300 amotinados que irão incendiar a llha Grande no dia em que a comida faltar"8.

Pensando na condição específica dos sujeitos que passam pela abordagem policial no Brasil e sobre quem recaem várias formas de julgamento e estereotipagem social e institucional, Michel Misse nos apresenta o conceito de sujeição criminal:

O conceito de "sujeição criminal" é proposto com a finalidade de determinar três dimensões incorporadas na representação social do "bandido" e de seus tipos sociais. A primeira dimensão é a que seleciona um agente a partir de sua trajetória criminável, diferenciando-o dos demais agentes sociais, através de expectativas de que haverá, em algum momento, demanda de sua incriminação; a segunda dimensão é a que espera que esse agente tenha uma "experiência social" específica, obtida em suas relações com outros bandidos e/ou com a experiência penitenciária; a terceira dimensão diz respeito à sua subjetividade e a uma dupla expectativa a respeito de sua autoidentidade: a crença de que o agente não poderá justificar sensatamente seu curso de ação ou, ao contrário, a crença em uma justificação que se espera que esse agente dê (ou que possa ser dada legitimamente a ele) para explicar porque segue reiteradamente nesse curso de ação criminável (MISSE, 1999, p. 72).

A definição de Misse relembra a dimensão política e social da alteridade na figura do pária que, segundo Eleni Varikas (2014, p. 61), "[...] designa (e denuncia) os procedimentos de exclusão do outro, em nome do princípio da unidade do gênero humano [...]". Também podemos remeter ao

\footnotetext{
${ }^{4}$ RIBEIRO, Ultima Hora, Rio de Janeiro, 01/08/1960; 02/08/1960; 03/08/1960; 04/08/1960.

5 A escrita original das fontes consultadas foi mantida em todas as citações. RIBEIRO, Ultima Hora, Rio de Janeiro, 01/08/1960.

${ }^{6}$ RIBEIRO, Ultima Hora, Rio de Janeiro, 01/08/1960.

7 Cf. SANTOS (2018).

${ }^{8}$ RIBEIRO, Ultima Hora, Rio de Janeiro, 04/08/1960.
} 
conceito de "inimigo", descrito por Eugenio Raúl Zaffaroni (2015): um indivíduo que deve ser encarado meramente como daninho e digno apenas de contenção ou eliminação, tendo seu caráter de pessoa negado. É evidente, ao longo da série, o peso da sujeição criminal e formas variadas de marginalização social sobre os detentos, reforçando leituras sociais da violência como algo intrínseco ao indivíduo encarcerado e inextirpável dele. Além de reforçar a sujeição criminal, essa via única de abordagem da violência endógena, de detento para detento, ignora a violência generalizada e institucional tão presente na história da llha Grande ${ }^{9}$. Também é interessante notar a ausência de denúncias a agentes policiais no discurso do jornal, que apresenta o Estado como componente impessoal e abstrato, emergente do mau funcionamento da máquina pública e manifesto nas más condições de infraestrutura, abastecimento e trabalho. Como veremos adiante, esse padrão de enquadramento não se manteria no ano seguinte.

\section{Os cárceres da Estação Ferroviária Central do Brasil}

A série de oito reportagens publicadas nos dias 22, 23, 25, 26, 27, 28, 29 e 30 de setembro de 1961, também realizadas pelo repórter Amado Ribeiro, denuncia as condições dos cárceres subterrâneos da Estação Ferroviária Central do Brasil (EFCB), também conhecida como Estação D. Pedro II, situada na região central da cidade do Rio de Janeiro. As primeiras reportagens enfatizam problemas de infraestrutura, higiene e superlotação, atribuindo termos de comiseração aos detentos, como: "vítimas", "desgraçados", "pobres diabos sem culpa formada", "infelizes", "sujos", "imundos". Entre os termos atribuídos às instalações, encontramos: "masmorras", "celas malditas", "câmaras da morte", "porões infectos", "celas de tortura" e "campos de concentração". De maneira geral, a ênfase sobre os detentos se reduz ao longo da série, como também a saliência das reportagens se reduz a partir da sexta ${ }^{10}$. $O$ foco passa gradativamente para as torturas perpetradas por policiais, com base em casos pontuais testemunhados e suas investigações ${ }^{11}$.

Enfatiza-se, em todas as reportagens, a morte do pintor Jorge Pascoal da Silva, 29 anos, tuberculoso, morto em 14 de setembro de 1961 após ser torturado e espancado por guardas do serviço de policiamento da unidade sob a alegação de ter roubado fios da EFCB. Três outras vítimas testemunharam a morte do pintor, que teria chegado ao hospital com várias escoriações no corpo, sinais de tortura e uma perfuração no abdômen provocada por uma barra de ferro. Em 23 de setembro, o jornal relata que Jorge Pascoal da Silva foi:

[...] espancado a sôcos, pontapés e golpes de barras de ferro; forçado a engolir urina de outros presos; obrigado a engolir toda uma lata de vaselina; colocado, por longo tempo, no "pau-dearara" e, finalmente, submetido a sevícias animalescas, para cuja descrição, dado o baixo instinto dos autores, o repórter não encontra têrmos condignos. ${ }^{12}$

Em 26 de setembro menciona-se que a vaselina seria, na verdade, "[...] uma pomada (lata grande) medicinal usada diariamente por um dos investigadores da EFCB para tratar de uma extensa ferida que tem na perna direita" ${ }^{\prime 3}$. Com base nos relatos das três testemunhas (Jaime Dias Ferreira, Rubem Francisco e Sebastião dos Anjos), cerca de dez investigadores da EFCB interrogavam e espancavam os detidos sem motivo. Observa-se certa constância na forma como as torturas eram praticadas: telefones, paus-de-arara, agressões com palmatórias, cassetetes, barras de ferro e tábuas de construção, ingestão forçada da supracitada pomada, além de alguns

\footnotetext{
${ }^{9}$ Cf. SANTOS (2018); RIBEIRO (s.d.).

10 Empregamos "saliência" como um conjunto de recursos textuais e não-textuais usados para capturar a atenção visual do leitor e estabelecer uma hierarquia de leitura para a página do jornal. Tais recursos compreendem escalas, contrastes, imagens e convenções culturais que resultem numa rápida orientação endógena da atenção visual (ANTONIO, 2017; MCCOMBS, 2009).

11 RIBEIRO, Ultima Hora, Rio de Janeiro, 22/09/1961; 23/09/1961; 25/09/1961; 26/09/1961; 27/08/1961; 29/09/1961; 30/09/1961.

12 RIBEIRO, Ultima Hora, Rio de Janeiro, 23/09/1961.

13 RIBEIRO, Ultima Hora, Rio de Janeiro, 26/09/1961.
} 
detentos serem obrigados a urinar na boca de outros ou a estuprá-los ${ }^{14}$. A reportagem de 26 de setembro chama a atenção para a deficiência na perna esquerda de Rubem Francisco, "[...] consequência de uma paralisia infantil que o levou a ser mendigo até bem pouco tempo", salientando que, apesar de sua condição física, ele não foi poupado pelos "carrascos". E, na mesma reportagem, Rubem relata que policiais ameaçaram jogá-lo "[...] amarrado dentro de um saco, no Rio Guandu"15.

O jornal enquadra os detentos como injustiçados, vítimas da arbitrariedade das instituições e do despreparo de seus agentes. Os policiais, supostamente, consideravam os detentos como desprovidos de humanidade. Todavia, as formas de desumanização e pseudoespeciação no trato dos agentes para com os detentos são instrumentalizadas contra os próprios agentes no texto das reportagens. Eles seriam: "bêstas policiais", "bêstas humanas", "monstros", "feras da central", "gestapo da Pedro II", com métodos semelhantes aos "dos assassinos e carrascos da SS nazista"16. Esses padrões de metáforas compõem um recurso frequente em processos de delimitação e exclusão social (SAPOLSKY, 2017; VARIKAS, 2014).

Nota-se, claramente, uma inversão no discurso do jornal sobre aqueles que devem ser desumanizados, mas a visão sobre o Estado não é nada simplificada, e a série tende a explorar o assunto como uma complexa malha interinstitucional. Apresentam-se responsabilidades, cobranças e acusações cruzadas entre a alta direção da EFCB, o delegado e a Assembleia Legislativa da Guanabara (ALEG). O jornal traz uma noção multifacetada que lembra a leitura de Pierre Bourdieu (2014) sobre o Estado como um "campo do poder" onde se desenrolam diversas disputas políticas. Em 25 de setembro de 1961, o jornal fala de "crime oficializado" e "pistoleiros oficiais" ${ }^{17}$, enfatizando a responsabilidade estatal, mas o peso das acusações cai assimetricamente sobre poucos agentes, como o policial Pedro Aureliano de Melo (vulgo Pedro "Parabellum") e, em menor grau, os policiais Osvaldo Lima e José Maria da Costa Brito Filho (vulgo "Pára-Raios"), todos acusados de envolvimento direto na morte do pintor Jorge Pascoal da Silva e na tortura de outros detentos.

Em 26 de setembro, o jornal comenta que o deputado estadual e líder do PTB junto à ALEG, Saldanha Coelho, teria abordado o caso em seu discurso no plenário, apelando ao Ministro da Justiça, ao governo do estado e à direção da ferrovia ${ }^{18}$. Na reportagem do dia seguinte, o diretor da EFCB, Jorge de Abreu Schiling, teria declarado a instauração imediata de processo administrativo, segundo o Estatuto dos Funcionários Públicos Civis da União, ao tomar ciência dos crimes de tortura. A $11^{\text {a }}$ Delegacia de Polícia que, na época, funcionava nas dependências da EFCB, teria tomado providências para instauração de inquérito policial. A mesma edição fala da suspensão por trinta dias dos policiais Pedro Aureliano de Melo, José Maria da Costa Brito Filho e do fiscal Mário José Fernandes, este último por sua alegada omissão e conivência. O policial Osvaldo Lima, empregado sob o regime da Consolidação das Leis do Trabalho, teria sido dispensado ${ }^{19}$.

Entre as acusações feitas contra Pedro Aureliano de Melo, mencionam-se ameaças de morte que o policial fizera aos membros da comissão de inquérito, tentando barrar as investigações ${ }^{20}$. Apesar das menções ao nome do policial com várias acusações ao longo da série, sua defesa surge na última reportagem, em 30 de setembro, quando o jornal traz seu depoimento prestado à $11^{a}$ Delegacia de Polícia. O policial teria negado qualquer envolvimento na morte do pintor ou tortura dos outros detentos, estando apenas de plantão no dia. Segundo o policial, o pintor foi torturado na Marítima - um setor da EFCB localizado no cais do porto - pelos policiais João Amâncio, Antônio Tenório e Mário Fernandes que, inclusive, ofereceu suborno para que Pedro

\footnotetext{
${ }^{14}$ RIBEIRO, Ultima Hora, Rio de Janeiro, 23/09/1961; 25/09/1961.

15 RIBEIRO, Ultima Hora, Rio de Janeiro, 26/09/1961.

16 RIBEIRO, Ultima Hora, Rio de Janeiro, 22/09/1961; 23/09/1961; 25/09/1961; 26/09/1961; 27/08/1961; 29/09/1961; 30/09/1961.

${ }^{17}$ RIBEIRO, Ultima Hora, Rio de Janeiro, 25/09/1961

${ }^{18}$ RIBEIRO, Ultima Hora, Rio de Janeiro, 26/09/1961.

19 RIBEIRO, Ultima Hora, Rio de Janeiro, 27/09/1961.

${ }^{20}$ RIBEIRO, Ultima Hora, Rio de Janeiro, 26/09/1961.
} 
acobertasse o $\operatorname{caso}^{21}$. A série é encerrada sem maiores esclarecimentos quanto às novas denúncias feitas por Pedro Aureliano de Melo.

\section{As Prisões da Invernada de Olaria e Alto da Boa Vista}

A série de cinco reportagens publicadas nos dias 5, 6, 7, 9 e 10 de outubro de 1961, realizadas pelo repórter Amado Ribeiro, relata torturas nos xadrezes da Invernada de Olaria e do Comissariado do Alto da Boa Vista, bem como as condições dessas instalações. A Invernada de Olaria era uma Subseção de Vigilância situada na rua Paranapanema, no bairro de Olaria (OLIVEIRA, 2016), e o Comissariado do Alto da Boa Vista situava-se na confluência das vias que levavam à Mesa do Imperador, à Vista Chinesa e a Furnas-Jacarepaguá (GÓMEZ, 2015). Esses estabelecimentos passaram a receber estudantes, professores, operários e presos políticos durante a crise decorrente da renúncia de Jânio Quadros em agosto do mesmo ano. As matérias enfatizam problemas de infraestrutura, higiene, abusos de autoridade e superlotação, atribuindo às instalações termos como "celas negras de torturas", "campos de concentração", "jaulas", "cárceres infectos e úmidos", "masmorras", "ratoeiras humanas" e "Dispositivo Golpista". A ênfase das primeiras reportagens recai sobre a infraestrutura do Comissariado do Alto da Boa Vista e da Invernada da Olaria para então, nas últimas reportagens, trazer o relato de vítimas de arbitrariedades policiais. A saliência se reduz gradativamente, com ausência de chamadas de capa a partir da quarta reportagem ${ }^{22}$.

Após denúncias realizadas junto à ALEG, os cárceres do Alto da Boa Vista e da Invernada foram desativados, permitindo que o repórter adentrasse suas instalações e compreendesse a dinâmica de cada local. Sob a direção do delegado Cecil Borer, a Invernada de Olaria possuía seis celas com capacidade para 30 detentos cada, todas com as paredes pintadas de preto, separadas por uma antessala e uma porta de aço. Entretanto, segundo informações dadas à reportagem, as celas chegaram a acomodar cerca de 300 detentos durante a crise política de agosto. Durante esse período, Cecil Borer impediu que até mesmo os policiais que ali trabalhavam soubessem os nomes dos presos. A relação dos detidos na Invernada ficava em posse da Delegacia de Vigilância, situada próxima do Palácio Itamaraty ${ }^{23}$.

"Tudo parece ter sido elaborado, no Alto da Boa Vista, por um cérebro diabólico, um estudioso profundo da técnica das 'SS' de Hitler"24, são as palavras do repórter a respeito da instituição dirigida pelo coronel Ardovino Barbosa. O Comissariado do Alto da Boa Vista possuía instalações próprias para a tortura de detentos, majoritariamente estudantes e líderes sindicais, sendo ativamente usadas durante a crise política. Assim que a equipe de reportagem adentrou $o$ recinto, acompanhada de um guarda, teriam se deparado com uma palmatória em cima de uma mesa, "[...] como se fôsse um instrumento de trabalho"25. O espaço dispunha de seis celas onde os detentos dormiam no chão de cimento batido, geralmente nus. Cada cela possuía um sistema de canos controlado pelos guardas, facilitando a tortura dos detentos através da privação de água. $A$ entrada do prédio, que por fora lembraria um posto de saúde, se dava por uma pesada porta de aço. A equipe de reportagem relata também uma "sala de banhos" de dois por quatro metros, com três chuveiros de água gelada. Segundo a reportagem, "[...] os 'banhos' eram aplicados em políticos e estudantes sistemàticamente depois da meia-noite, e duravam até às 6 horas da manhã"26, sendo os detentos posteriormente levados a uma sala adjacente, recoberta de cimento e com apenas um vaso sanitário. O jornal encerra a reportagem de 6 de outubro acusando o promotor Newton de Barros Vasconcelos de, sob ordens do governador Lacerda, ter providenciado cubículos no presídio

\footnotetext{
${ }^{21}$ RIBEIRO, Ultima Hora, Rio de Janeiro, 30/09/1961.

22 RIBEIRO, Ultima Hora, Rio de Janeiro, 05/10/1961; 06/10/1961; 07/10/1961; 09/10/1961; 10/10/1961.

${ }^{23}$ RIBEIRO, Ultima Hora, Rio de Janeiro, 05/10/1961.

${ }^{24}$ RIBEIRO, Ultima Hora, Rio de Janeiro, 06/10/1961.

${ }^{25}$ RIBEIRO, Ultima Hora, Rio de Janeiro, 06/10/1961.

${ }^{26}$ RIBEIRO, Ultima Hora, Rio de Janeiro, 06/10/1961.
} 
de llha Grande, também chamado de "Inferno Verde", para aprisionar os presos políticos. Mencionase também que o Comissariado do Alto da Boa Vista seria um "centro de triagem" para que os presos políticos fossem encaminhados à llha Grande.

As reportagens seguintes (7, 9 e 10 de outubro de 1961) trazem relatos de tortura e abusos contra estudantes e dirigentes sindicais por policiais da Invernada de Olaria e do Alto da Boa Vista, dentro e fora de suas dependências. Em 9 de outubro, o jornal menciona ordens do governador para conter manifestações a favor da posse de João Goulart na presidência da República, consequência da renúncia de Jânio Quadros em agosto do mesmo ano, contando "[...] com a ajuda do General Sizeno Sarmento, Coronéis Ardovino Barbosa e Lauro Pinto e o Inspetor Cecil Borer, para a prática de seguidos atentados que incluíram prisões e espancamentos de estudantes, professôres e líderes operários [...]"27.

A edição de 7 de outubro traz o relato de dois estudantes que teriam sido vítimas de abusos policiais, envolvendo prisões indevidas, torturas, espancamento e apreensão de pertences sem mandado judicial. Uma estudante testemunha que, na manhã de 28 de agosto, teve sua residência invadida por cerca de nove agentes em busca de "agitadores" e mimeógrafos que ali se encontravam, pertencentes a um Diretório Central dos Estudantes. Após a revista, a estudante, sua mãe e sua irmã foram presas. Os policiais teriam confiscado os mimeógrafos, uma máquina de escrever e 130 mil cruzeiros em espécie. As máquinas foram devolvidas posteriormente, quebradas, e o dinheiro sumiü28.

O outro estudante conta que foi abordado ao lado de uma banca de jornal, na Avenida Rio Branco, por cerca de dez ou doze homens, todos armados, que o levaram a um prédio ao lado da Maison de France $^{29}$ para ser espancado. O jornal relata que, devido aos ferimentos, o estudante não foi transferido à Invernada de Olaria e nem ao Alto da Boa Vista, mas que alguns de seus conhecidos haviam passado pelas "salas de banho" após o espancamento. O estudante finaliza seu relato mencionando que Lacerda, enquanto decidia os rumos do país, "[...] preferiu que o povo fôsse espancado e silenciado a borrachadas e tiros. Êle se esquece que um povo não se cala nunca, principalmente quando é esbulhado e usurpado" ${ }^{30}$. São constantes as acusações ao governador, e a menção a "ordens", sem referência a documentos, ignora possibilidades de dispersão do poder de mando e janelas de corrupção ou negligência decorrentes da própria dinâmica do Estado, já identificado como uma complexa malha interinstitucional na série anterior. Para o leitor contemporâneo, entretanto, a obra de Dulles (2000) e as cartas de Lacerda (MELLO E SOUZA; COELHO, 2014) confirmam o apoio do governador às medidas repressivas de agosto de 1961, nos permitindo uma hipótese a ser mais bem explorada para a mudança de enquadramento noticioso ao longo das séries.

Nas duas últimas reportagens da série, o jornal entrevista os dirigentes sindicais Artur Cantalicci, Alberto Sampaio, Jorge Fernando e Giovanni Romita, presos durante as manifestações que sucederam à renúncia de Jânio Quadros. Segundo a reportagem, o destino da maioria dos dirigentes seria o presídio de llha Grande para serem fuzilados. Apesar das torturas, todos teriam escapado. Entre os abusos relatados constam privação de água e comida, espancamentos, torturas e ameaças de fuzilamento, quase sempre nas dependências da Invernada de Olaria e no Alto da Boa Vista. O portuário Artur Cantalicci, capturado por policiais na Ponte dos Marinheiros quando distribuía panfletos com cópia do mandado de segurança a favor da posse de João Goulart, foi levado ao posto policial da Leopoldina e relatou ao jornal que ficou preso durante seis dias junto a outros detentos, que eram levados para interrogatórios na madrugada e não mais voltavam. Alberto Sampaio foi preso junto a nove amigos, sendo transferido da Delegacia de Vigilância até a

\footnotetext{
${ }^{27}$ RIBEIRO, Ultima Hora, Rio de Janeiro, 09/10/1961.

${ }^{28}$ RIBEIRO, Ultima Hora, Rio de Janeiro, 07/10/1961.

29 Teatro e centro de convenções anexo ao Consulado-Geral da França no Rio de Janeiro.

30 RIBEIRO, Ultima Hora, Rio de Janeiro, 07/10/1961.
} 
Invernada de Olaria num caminhão fechado. Nas dependências da Invernada, Alberto foi colocado numa cela com outras quarenta e duas pessoas, na maioria estudantes ${ }^{31}$.

A desumanização do detento atribuída pelo jornal às instituições policiais encontra espaço em poucos trechos nessa série, nas "jaulas" ou "ratoeiras humanas"; menciona-se que "[a] alimentação, era o que se supunha, vinha de restos dos cães da Polícia Militar, cujos canis estão ao lado"32. A perseguição a estudantes e operários já permite inferir, em 1961, a presença de um "fantasma condensado da repressão", ainda que Misse (1999) situe tal fantasma como fruto do regime autoritário de 1964. Um fantasma social é criado quando o crime ou ato desviante sai da esfera individual e passa a ser elemento fundamental na construção de tipos sociais. No caso do fantasma condensado, colocam-se sob o mesmo crivo os diversos criminosos (potenciais presos comuns) e os agitadores de esquerda (potenciais presos políticos), nesse caso os estudantes supostamente vinculados a células comunistas e os operários organizados.

\section{As "celas-catacumbas" da Central do Brasil}

A série de cinco reportagens publicadas nos dias 3, 4, 6, 7 e 8 de novembro de 1961, realizadas pelo repórter Silvio Paixão, retoma as denúncias sobre os cárceres subterrâneos da EFCB. A série aborda a superlotação das celas e o tratamento dos detentos, bem como problemas de infraestrutura que impactam nas condições de higiene, abastecimento de água, ventilação e alimentação, atribuindo às instalações termos como "celas-catacumbas", "indústrias do crime", "jaulas", "depósito de fantasmas" e "celas da masmorra da Central do Brasil". A ênfase das cinco reportagens recai sobre as condições dos detentos, apresentando casos pontuais, e também sobre as diligências realizadas pelos deputados da ALEG Adalgisa Nery (Partido Socialista Brasileiro PSB), Hércules Corrêa (PTB) e Lygia Lessa Bastos (União Democrática Nacional - UDN), que buscaram esclarecimentos sobre as condições dos cárceres junto às autoridades policiais. A alta saliência é mantida no decorrer da série, com fotografias em todas as reportagens, mas sem chamadas de capa. Nota-se, em relação às séries anteriores, um aumento do sensacionalismo, sobretudo ao descrever os detentos, utilizando termos como "sucatas humanas", "feras que foram homens", "débeis mentais", "mulheres e crianças, como cães", "dementes" e "prostitutas". Novamente, o jornal atribui certa desumanização do detento às instituições policiais, tentando criar empatia no leitor através da negação de empatia na relação policial-detento, mas esta série difere das anteriores por não associar as condições de detenção ao regime nazista ${ }^{33}$. Tais mudanças estilísticas possivelmente decorrem da mudança de autoria.

A reportagem de 3 de novembro, a primeira da série, menciona que leitores do Ultima Hora, que transitavam próximos à EFCB, comunicaram sobre um tumulto no posto policial da dependência, decorrente de uma rebelião na ala masculina. O comunicado fez a redação entrar em contato com parlamentares da ALEG, que foram até o local para averiguar as condições dos cárceres. O delegado Ary Leão, da referida delegacia de polícia, em conversa com os parlamentares, dissera não haver lugar para alocar os presos, que a situação em que os mesmos se encontravam seria um problema da administração e que as condições de sua delegacia eram precárias. O conflito de interesses entre instâncias distintas do jogo político-administrativo novamente evidencia a complexa malha interinstitucional que compõe o Estado, com diversos agentes disputando a obtenção, alocação, utilização e fiscalização de recursos. O jornal traz a réplica dos parlamentares ao delegado, ironizando o fato deste ter comunicado apenas oralmente seus superiores sobre as más condições das instalações, não produzindo qualquer prova documental ${ }^{34}$. Na edição do dia seguinte, Maria Soares Meirelles, dona-de-casa recém-liberada das

\footnotetext{
${ }^{31}$ RIBEIRO, Ultima Hora, Rio de Janeiro, 09/10/1961; 10/10/1961.

32 RIBEIRO, Ultima Hora, Rio de Janeiro, 09/10/1961.

33 PAIXÃO, Ultima Hora, Rio de Janeiro, 03/11/1961; 04/11/1961; 06/11/1961; 07/11/1961; 08/11/1961.

34 PAIXÃO, Ultima Hora, Rio de Janeiro, 03/11/1961.
} 
"celas-catacumbas", concede uma entrevista ao jornal alegando que foi presa apenas por não portar os documentos e que fugiria para o interior do estado do Rio de Janeiro com o nome trocado. $\mathrm{Na}$ mesma cela de Maria havia outras três mulheres doentes e sem tratamento adequado ${ }^{35}$.

$\mathrm{Na}$ edição de 6 de novembro, uma das prisioneiras menciona que bastava estar sem documento para que o delegado classificasse as mulheres como prostitutas, prendendo-as de forma ilegal e sem culpa formada ${ }^{36}$. O jornal menciona que o posto policial da EFCB seria um dos "quartéis-generais" de Cecil Borer, cuja finalidade "[c]onsiste em recolher mendigos, em carros fechados da Polícia, e despejá-los, como lixo, à noite, em matagais fora da GB [Guanabara]. Êste plano tem por objetivo "cuidar da aparência da cidade'"37.

Durante sessão da ALEG, em 6 de novembro de 1961, a deputada Adalgisa Nery teria abordado o caso das prisões da EFCB e mencionado que foi agredida pelo sargento Wolfran Moreira de Souza, da Polícia Militar. O líder do PTB, Saldanha Coelho, teria dado o prazo de 24 horas ao chefe de polícia, Segadas Viana, para prestar esclarecimentos sobre os fatos. Ao presidente da ALEG, Lopo Coelho (Partido Social Democrático - PSD), teria sido enviado um requerimento convocando o secretário de Segurança, Sizeno Sarmento, para esclarecer sobre a agressão à deputada e sobre as condições das celas da EFCB. Enquanto Saldanha Coelho discursava sobre o caso, Segadas Viana teria telefonado ao parlamentar informando que o policial acusado de agredir a deputada Adalgisa Nery fora afastado do cargo para a investigação do fato mediante inquérito, levando-o a cancelar o requerimento ${ }^{38}$.

Em depoimento ao jornal, Segadas Viana relata que a $11^{\text {a }}$ Delegacia de Polícia passou a funcionar na EFCB após uma ordem de despejo na rua Barão de São Félix, imóvel de propriedade particular onde funcionava, e sua transferência dependeria de uma verba negada pela própria ALEG, no valor de 30 milhões de cruzeiros. Novamente evidencia-se o emaranhado de intrigas e responsabilidades entre as diversas instâncias do Estado. Apesar desta série se desenrolar no âmbito político-administrativo da Guanabara, o jornal não vincula o nome de Lacerda. Menciona-se "[...] que as escabrosas torturas (sêde, promiscuidade e sujeira) continuavam. A mesma quantidade de mulheres, crianças e velhos comprimidos como sardinhas em latas nos cubículos infectos" ${ }^{\text {" }}$. Além disso, relata-se que apenas cinco homens foram presos legalmente, estando os noventa e cinco detentos restantes de forma ilegal, sem registro.

\section{Considerações e hipóteses}

Entre as séries de reportagens realizadas por Amado Ribeiro nota-se, inicialmente, um discurso que enfatiza a sujeição criminal do detento, mas que se modificaria já na segunda série, enfatizando as arbitrariedades policiais e invertendo a lógica de desumanização do detento para o policial, inclusive atribuindo uma visão desumanizadora do policial para com o detento. Outro movimento notado nas séries de Amado Ribeiro é o envolvimento de escalas cada vez mais altas do Estado nas denúncias, culminando em referências diretas ao governador Carlos Lacerda na terceira série de reportagens. Também nota-se o uso de termos depreciativos sobre o Estado, suas instituições, seu modus operandi e os policiais, eventualmente remetendo-os ao regime nazista ${ }^{40}$.

Tendo um mesmo repórter como parâmetro frente ao fluxo de acontecimentos, as mudanças no discurso podem indicar motivações políticas para as formas de enquadramento e apresentação

\footnotetext{
35 PAIXÃO, Ultima Hora, Rio de Janeiro, 04/11/1961.

36 PAIXÃO, Ultima Hora, Rio de Janeiro, 06/11/1961.

37 PAIXÃO, Ultima Hora, Rio de Janeiro, 07/11/1961.

38 PAIXÃO, Ultima Hora, Rio de Janeiro, 07/11/1961.

39 PAIXÃO, Ultima Hora, Rio de Janeiro, 07/11/1961.

${ }^{40}$ A variação nos discursos de Amado Ribeiro parece contrariar a descrição do jornalista fornecida por Benício Medeiros (2009), para quem Amado sustentava uma visão maniqueísta do policial sempre bom e do bandido sempre mau. Amado foi personagem de destaque no Ultima Hora (RIBEIRO, s.d.) e chegou a ser chefe de redação da seção policial em fins da década de 1960 (ANTONIO, 2017), de modo que visões simplistas de seu estilo e de sua visão de mundo dificilmente encontrariam amparo em análises mais amplas de sua produção textual.
} 
do assunto narrado, assim como a evocação de sensações e emoções do público leitor como forma de mobilizar oposição ao governo. No longo hiato entre as duas primeiras séries, Carlos Lacerda assumira o governo da Guanabara como primeiro governador eleito do novo estado, e o histórico de conflitos precedentes entre Lacerda e o Ultima Hora reforça a hipótese de oposição política através do enquadramento, sendo importante considerar o uso instrumental da imprensa pela e para a política nesse período, quando eram frequentes as relações de posse ou direção entre políticos e veículos de imprensa. Veja-se que Lacerda funda o jornal Tribuna da Imprensa em 194941; Chagas Freitas funda O Dia em 1950 e, no mesmo ano, adquire A Notícia junto com Ademar de Barros; Tenório Cavalcanti funda A Luta Democrática em 1954; e San Tiago Dantas adquire o Jornal do Commercio em 1957. Ademais, a deputada Adalgisa Nery, que visitou as dependências da EFCB junto a outros parlamentares, também escrevera para o Ultima Hora sobre temáticas políticas em sua coluna fixa, "Retrato sem Retoque", entre os anos de 1954 e 1964 (BARBOSA, 2007; CAMPOI, 2008).

Todavia, seria simplista creditar a mudança notada no discurso do jornal somente à posse do novo governador. Desta forma, a mobilização da imprensa após a morte de Nestor Moreira em 1954 pode ter se somado a outras questões políticas entre 1960 e 1961, resultando nas novas formas de enquadramento das forças policiais e do governo da Guanabara nas páginas do Ultima Hora. No mesmo interstício entre a primeira e a segunda série analisadas, temos a renúncia do presidente da República Jânio Quadros, usualmente apresentada a partir de seus bastidores em Brasília ou da Campanha da Legalidade no estado do Rio Grande do Sul42, mas é no estado da Guanabara que o termo "crise política" se apresenta enfático ${ }^{43}$. A ampla percepção pública do aparato policial como uma força autoritária soma-se entre os elementos de descrédito ao governo estadual e talvez as consequências desse momento se reflitam e se reforcem ao longo do tempo até eventos posteriores.

Maria Victoria Benevides (1999) e Boris Fausto (2010), entre outros historiadores, apontam que fatos diretamente ligados à renúncia de Jânio possuem Lacerda como protagonista, quando este realiza um pronunciamento na imprensa em 24 de agosto de $1961^{44}$. Lacerda acusa Jânio de intenções golpistas, as quais ele teria descoberto ao ser convidado pelo ministro da Justiça, Oscar Pedroso Horta, para também participar do suposto golpe. No dia seguinte, após as comemorações do dia do soldado, Jânio entregara sua carta-renúncia ao Congresso Nacional. Nos primeiros momentos após a renúncia, Lacerda aparentava uma postura conciliatória e de apoio à posse de João Goulart, conforme nota expedida pelo governo da Guanabara em 26 de agosto e reproduzida em alguns jornais. "O regime democrático será mantido e garantida a liberdade dentro da ordem. [...] O governador permanece no seu posto no Guanabara, junto aos demais governos, à legalidade democrática, à paz dos lares e ao futuro da nossa pátria"45.

Entretanto, conforme Mendonça (2002, p. 267), na noite de 25 de agosto de 1961, o ministro Horta "[...] ocupou os microfones à Rádio Guanabara [...]" para se defender da uma suposta tentativa de aliciar Lacerda para um golpe. Os transmissores da emissora teriam sido quebrados pela polícia

\footnotetext{
${ }^{41}$ Em dezembro de 1960, quando da posse de Lacerda como governador da Guanabara, a direção do jornal Tribuna da Imprensa foi passada para seu filho, Sérgio de Lacerda. Ao final de 1961, em função de problemas financeiros, o jornal foi vendido para Manuel Francisco do Nascimento Brito, sendo novamente vendido para Hélio Fernandes em dezembro de 1962. Apesar das mudanças de posse e direção, o jornal se manteve alinhado aos interesses de Carlos Lacerda, que permanecia assinando artigos sob o pseudônimo de Júlio Tavares (DULLES, 2000).

42 A Campanha da Legalidade foi encabeçada pelo então Governador do Rio Grande do Sul, Leonel Brizola, que com o apoio do III Exército, da população local e amplo uso de radiodifusão conseguiu mobilizar parcelas significativas da opinião pública para garantir a sucessão presidencial de Jânio Quadros nos moldes constitucionais, apesar de uma tentativa de veto de alguns setores militares ao então vice-presidente João Goulart.

${ }^{43}$ Amir Labaki (1986) aponta diversos focos de repressão pelo Brasil após a renúncia, como nos estados de Minas Gerais, Pernambuco e São Paulo. Entretanto, o autor prioriza as situações do Rio Grande do Sul, Brasília e da Guanabara.

${ }^{44}$ Cabe-nos pontuar que a hipótese mais comum na literatura é a de que a renúncia seria uma tentativa de golpe frustrada, orquestrada pelo próprio Jânio (BENEVIDES, 1999; CHAGAS, 2014; FAUSTO, 2010; LABAKI, 1986).

45 Jornal do Brasil, 26/08/1961b.
} 
guanabarina, impedindo Horta de relatar sua versão, que seria reproduzida em alguns jornais do dia seguinte. Apesar dos termos usados por Mendonça sugerirem que Horta compareceu ao estúdio da Rádio Guanabara, os jornais nos levam a crer que essa apenas retransmitiu o pronunciamento do ministro realizado em São Paulo ${ }^{46}$. Segundo a edição de 26 de agosto de 1961 do Jornal do Brasil, o investigador Hélio Guaíba Nunes, da Delegacia de Vigilância, também compareceu à Rádio Jornal do Brasil solicitando que o discurso não fosse transmitido "[...] por ser considerado subversivo" 47 .

Mendonça (2002) e Dulles (2000) narram que a reação popular nas ruas foi imediata quando da renúncia de Jânio. Uma greve deflagrada pelo Sindicato dos Ferroviários somava-se às multidões reunidas em frente à embaixada dos Estados Unidos, aos gritos de "Jânio sim! Lacerda não!". Nesse cenário conturbado, o alinhamento de Lacerda aos ministros militares em seu veto à posse do vice-presidente João Goulart, temendo uma suposta ameaça comunista, inflamaria ainda mais os ânimos. Um manifesto de líderes sindicais apoiaria a greve dos ferroviários, exigindo uma greve geral, que não veio a ocorrer, embora contasse com a solidariedade de trabalhadores portuários, marítimos, metalúrgicos e têxteis. "Com a prisão de alguns líderes operários, inclusive o presidente do sindicato dos gráficos da Guanabara, e a invasão dos sindicatos pelas tropas, o movimento de greve foi dominado" (DULLES, 2000, p. 60). Estudantes universitários também arriscaram uma greve em favor da legalidade, mas a Polícia Militar tomou conta da sede da União Nacional dos Estudantes (UNE), levando líderes estudantis a se asilarem em embaixadas diversas.

O crescimento de movimentos populares nas ruas ampliava as movimentações e ações do aparato repressivo, e a preocupação do governo estadual também se voltava à circulação de informações nos canais de maior amplitude. Mendonça (2002), Dulles (2000) e Labaki (1986) atentam que, além de emissoras de radiodifusão e televisão, a censura também atingiu os jornais, barrando notícias que denunciassem o impedimento da posse de João Goulart ou versassem sobre a Campanha da Legalidade no Rio Grande do Sul.

Segundo Lacerda, foi o coronel Golbery do Couto e Silva, secretário-geral do Conselho Nacional de Segurança, que pediu ao secretário de Segurança da Guanabara, general Siseno Sarmento, que instaurasse a censura no estado. Lacerda estava de acordo, pois considerava a censura "absolutamente indispensável". Para evitar que fossem divulgadas notícias que pudessem "pôr em perigo a ordem pública", soldados do Exército e da Polícia Militar exerceram uma "censura rigorosa" do rádio e da televisão. Agiram com igual rigor na censura da imprensa carioca, a começar pela invasão das redações do Diário Carioca e do Diário de Notícias na noite de sábado, 26 de agosto, para impedir a publicação de matéria que incluía o manifesto de Lott. Em todos os diários do Rio foram instalados oficiais do Exército para fiscalizar a censura de artigos. Em 28 de agosto, a Polícia Militar apreendeu a edição inteira do Correio da Manhã para o dia seguinte e prendeu o jornalista Batista de Paula, da Ultima Hora. No dia 29 a polícia apreendeu a edição do Diário de Notícias que continha uma entrevista com Goulart em Paris. A essa altura, uma proporção tão grande de noticiário estava sendo censurada que no dia 30 o Jornal do Brasil não circulou e o Diário de Notícias saiu com grandes espaços em branco em suas páginas (DULLES, 2000, p. 60).

Labaki (1986), Dulles (2000) e Mendonça (2002) mencionam que a Associação Brasileira de Imprensa $(\mathrm{ABI})$, sindicatos, proprietários e diretores de jornais remeteram telegramas à Sociedade Interamericana de Imprensa (SIP) denunciando as ações de Lacerda e pedindo sua expulsão da entidade. Estes telegramas teriam sido interceptados pelo governo estadual antes de chegarem ao destinatário. De alguma forma - mesmo que por vias distintas - a entidade tomou ciência dos fatos, e as cartas de Lacerda à $A B I$ e à SIP confirmam sua concordância com a censura e sua preocupação com uma suposta ameaça comunista (MELO E SOUZA; COELHO, 2014).

Em 30 de agosto de 1961, Raphael de Almeida Magalhães - chefe do Gabinete de Lacerda

\footnotetext{
46 Jornal do Brasil, 26/08/1961c.

47 Jornal do Brasil, 26/08/1961a.
} 
- reuniu-se com os proprietários e diretores de jornais para anunciar a suspensão da censura após determinação dos tribunais, mas a edição extra do Ultima Hora teve a circulação impedida por determinação do Ministério da Guerra no dia seguinte, e seus exemplares foram recolhidos por policiais (DULLES, 2000). A edição de $1^{\circ}$ de setembro do jornal critica a ação policial e reproduz o telegrama enviado à SIP, reafirmando a necessidade de expulsão do "[...] ex-jornalista Carlos Lacerda dos quadros daquela entidade, por absoluta incompatibilidade com a profissão jornalística"48.

Detendo o controle dos meios de comunicação, o governo estadual tentaria convencer a população de que o Congresso decretara estado de sítio - fato que não ocorrera - para que a polícia invadisse sindicatos e entidades estudantis livremente (MENDONÇA, 2002). Em 27 de agosto, o presidente do Sindicato dos Proprietários de Jornais, Chagas Freitas, enviou um telegrama a Lacerda mostrando sua indignação com a censura, alertando que "[...] nenhuma das garantias constitucionais está suspensa", cabendo ao governador cumprir a lei e determinar o restabelecimento da liberdade de imprensa no estado ${ }^{49}$.

Lacerda não foi o único jornalista a conquistar a repulsa da categoria profissional nesse contexto. Dulles (2000) atenta que o antigo redator-chefe do jornal Diário de Notícias, Ascendino Leite, então à frente do Serviço de Censura da Guanabara, foi acusado por ex-colegas de aproveitar-se de laços profissionais para obter informações privilegiadas e úteis à censura.

No dia 30 de agosto de 1961, o presidente do Congresso Nacional, senador Moura Andrade (PSD), optou por intervir sobre a censura e repressão no estado, enviando ao presidente da Câmara dos Deputados, Ranieri Mazzilli (PSD), um ofício que exigia providências a respeito. $E$, em $1^{\circ}$ de setembro, o deputado Armindo Marcílio Doutel de Andrade (PTB) denunciou ao plenário da Câmara o espancamento de José Gomes Talarico (PTB) pela polícia do estado (MENDONÇA, 2002).

Apresentada a crise da renúncia de Jânio no âmbito da Guanabara, percebemos que a crise política tomou tanto os poderes instituídos quanto parcelas populares. O contexto nos apresenta uma imprensa amplamente visada com fins instrumentais - seja para o controle das massas, através da censura, ou para o controle dos poderes instituídos, através das denúncias. Parece-nos plausível que o protagonismo de Lacerda e das forças policiais, com suas medidas repressivas, deixaria marcas em publicações posteriores, conforme nota-se ao longo das séries analisadas. Observe-se que a série sobre os cárceres da Invernada de Olaria e do Alto da Boa Vista trata exclusivamente de prisões políticas, diretamente associadas às manifestações pela posse de João Goulart.

Todavia, o peso desse episódio e seus desdobramentos, majoritariamente envolvendo violência policial, prisões políticas e censura aos meios de comunicação, não deve figurar sozinho entre as explicações possíveis para as mudanças de enquadramento empregadas pelo jornal Ultima Hora. A capacidade de Carlos Lacerda para mobilizar forças policiais guanabarinas deriva da mudança da capital federal para Brasília, criação do estado da Guanabara e transformação do Departamento Federal de Segurança Pública (DFSP) em Departamento Estadual de Segurança Pública (DESP) (OLIVEIRA, 2016); e embora os problemas de escassez e violência fossem antigos e recorrentes nos cárceres da Guanabara (OLIVEIRA, 2006; SANTOS, 2018; RIBEIRO, s.d.), tais mudanças levaram a um agravamento nesses problemas estruturais. Myrian Sepúlveda dos Santos (2018) aponta que diversos periódicos apresentaram denúncias concordantes sobre as prisões da Ilha Grande entre 1960 e 1961, decorrentes de uma drástica redução de verbas que culminou em certo caos administrativo e em receios recíprocos que elevavam as formas de violência endógena. Carlos Lacerda, inclusive, elegeu uma comissão para apresentar soluções ao problema penitenciário, culminando na desativação da Colônia Penal Cândido Mendes em 1962 (CHAGAS, 2014; SANTOS, 2018). Frederico de Oliveira (2016) também situa extinções, restabelecimentos e

\footnotetext{
48 Ultima Hora, 01/09/1961.

49 Ultima Hora, 29/08/1961.
} 
novas extinções das Subseções de Vigilância no período como exemplos de idas e vindas administrativas e injunções políticas. Desta forma, diversos fatores se somam e se reforçam enquanto motivações para as mudanças de enquadramento jornalístico.

A depreciação da instituição denunciada persiste na série de Sílvio Paixão, mas o repórter é menos enfático e não remete a práticas nazistas. Seu foco é descrever abusos e a presença de deputados nos cárceres, averiguando denúncias e seus desdobramentos. Analisando-se as quatro séries em sucessão, sem distinção de autor, alguns aspectos emergentes nas séries de Amado Ribeiro mantêm certa continuidade. Nessa quarta série temos representantes da ALEG adentrando os cárceres e debates sobre a condição carcerária adentrando as sessões da ALEG, o que evidencia o envolvimento de instâncias cada vez mais altas do Estado no conteúdo noticioso sobre o tema. Ainda acerca do Estado, este é apresentado como uma máquina multifacetada onde os papéis, responsabilidades e tomadas de decisão se articulam mediante disputas, nos moldes do "campo do poder" delineado por Bourdieu (2014).

A análise das quatro séries também sinaliza duas progressões mais ou menos previsíveis. A primeira diz respeito à reconfiguração do aparato repressivo no Brasil às vésperas do golpe militar de 1964, conforme nota-se na segunda série pela descrição de torturas usualmente atribuídas ao regime militar brasileiro, com uma repressão seletiva e aparente normalidade institucional. Janaína Teles (2013) aponta um aspecto importante a respeito do Estado brasileiro pós-1964: a pesquisadora diz não haver uma continuidade ou repetição das práticas, mas uma reorganização do aparelho repressivo anteriormente instalado. A segunda progressão diz respeito à posterior chacina de moradores de rua nos rios Guandu e da Guarda, denunciada pelo Ultima Hora no início de 1963 (DULLES, 2000; MENDONÇA, 2002). Como abordado, em 26 de setembro de 1961 um detento denunciou a ameaça de ser amarrado e colocado num saco para ser jogado no rio Guandu. Em 6 de novembro o jornal menciona que a EFCB seria um dos "quartéis-generais" de Cecil Borer, cujo objetivo era recolher moradores de rua na Guanabara para despejá-los fora do estado.

Embora o histórico de conflitos entre o Ultima Hora e Lacerda eleve as possibilidades de motivação política nas denúncias aos cárceres e nas posteriores denúncias de chacina, é importante salientarmos que essa constatação não diz respeito a uma via específica de causalidade, uma vez que a oposição ferrenha do jornal ao governador pode ter motivado tanto uma maior inventiva do jornal para destruir sua reputação, quanto uma fiscalização mais rigorosa das práticas e rotinas policiais do estado. $O$ conturbado cenário político da época facilitava tanto a oposição política pura e simples quanto grosseiras falhas administrativas, e o câmbio nas formas de enquadramento parece sinalizar a apropriação das segundas para instrumentalizar as primeiras.

\section{Fontes}

JORNAL DO BRASIL. Polícia proíbe Pedroso. Jornal do Brasil, Rio de Janeiro, 26/08/1961a. p. 1. Disponível em: http://memoria.bn.br/DocReader/030015_08/21358. Acesso em: 31 mai. 2019.

JORNAL DO BRASIL. Lacerda lamenta mas fica. Jornal do Brasil, Rio de Janeiro, 26/08/1961b. p. 4. Disponível em: http://memoria.bn.br/DocReader/030015_08/21361. Acesso em: 01 jun. 2019.

JORNAL DO BRASIL. Pedroso desmente golpe chamando Lacerda de boquirroto. Jornal do Brasil, Rio de Janeiro, 26/08/1961c. p. 10. Disponível em: http://memoria.bn.br/DocReader/030015_08/21367. Acesso em: 31 mai. 2019.

PAIXÃO, Silvio. Polícia Encurrala Mulheres e Crianças em Celas-Catacumbas. Ultima Hora, Rio de Janeiro, 03/11/1960. p. 7. Disponível em: http://memoria.bn.br/docreader/386030/75980. Acesso em: 15 mai. 2019.

PAIXÃO, Silvio. Crianças, mulheres e dementes apodrecem nas celas-catacumbas. Ultima Hora, Rio de Janeiro, 04/11/1961. p. 7. Disponível em: http://memoria.bn.br/DocReader/386030/71496. 
Acesso em: 15 mai. 2019.

PAIXÃO, Silvio. Feras que foram homens amontoadas em jaulas! Ultima Hora, Rio de Janeiro, 06/11/1961. p. 8. Disponível em: http://memoria.bn.br/DocReader/386030/71509. Acesso em: 15 mai. 2019.

PAIXÃO, Silvio. Prazo de 24 Horas Para o Chefe de Polícia Dar Explicação Sôbre as "CelasCatacumbas". Ultima Hora, Rio de Janeiro, 07/11/1961. p. 7. Disponível em: http://memoria.bn.br/docreader/386030/71528. Acesso em: 15 mai. 2019.

PAIXÃO, Silvio. Chefe de Polícia Culpa Deputados Pela Infâmia das "Celas-Catacumbas". Ultima Hora, Rio de Janeiro, 08/11/1961. p. 7. Disponível em: http://memoria.bn.br/docreader/386030/71544. Acesso em: 15 mai. 2019.

RIBEIRO, Amado. Monstros e loucos perambulam pela cidade dos mortos-vivos. Ultima Hora, Rio de Janeiro, 01/08/1960. p. 8. Disponível em: http://memoria.bn.br/docreader/386030/61261. Acesso em: 15 mai. 2019.

RIBEIRO, Amado. Fúria Assassina Dos Monstros Sòmente Contida Pelo Cansaço. Ultima Hora, Rio de Janeiro, 02/08/1960. p. 2. Disponível em: http://memoria.bn.br/docreader/386030/61269. Acesso em: 15 mai. 2019.

RIBEIRO, Amado. Monstros Fazem Churrasco de Mulheres e Querem Sobremesa. Ultima Hora, Rio de Janeiro, 03/08/1960. p. 14. Disponível em: http://memoria.bn.br/docreader/386030/61295. Acesso em: 15 mai. 2019.

RIBEIRO, Amado. Comida Está Acabando: 1.300 Detentos Prontos PARA MOTIM. Ultima Hora, Rio de Janeiro, 04/08/1960. p. 14. Disponível em: http://memoria.bn.br/docreader/386030/65505. Acesso em: 15 mai. 2019.

RIBEIRO, Amado. Bêstas Policiais Passeiam Impunes à Procura de Outras Vítimas na Central. Ultima Hora, Rio de Janeiro, 22/09/1061. p. 7. Disponível em: http://memoria.bn.br/docreader/386030/70970. Acesso em: 15 mai. 2019.

RIBEIRO, Amado. Policiais Obrigaram Inocente a Comer Uma Lata de Vaselina. Ultima Hora, Rio de Janeiro, 23/09/1061. p. 7. Disponível em: http://memoria.bn.br/docreader/386030/70984. Acesso em: 15 mai. 2019.

RIBEIRO, Amado. "QG" do Terror Policial Funciona Nos Subterrâneos da Estação "Pedro II"!. Ultima Hora, Rio de Janeiro, 25/09/1061. p. 8. Disponível em: http://memoria.bn.br/docreader/386030/70997. Acesso em: 15 mai. 2019.

RIBEIRO, Amado. Denúncia de UH Vai à Assembléia: Protesto Contra Campo de Concentração na Central. Ultima Hora, Rio de Janeiro, 26/09/1061. p. 7. Disponível em: http://memoria.bn.br/docreader/386030/71016. Acesso em: 15 mai. 2019.

RIBEIRO, Amado. Terceira vítima conta a UH: "eu vi o pintor tuberculoso morrer na tortura". Ultima Hora, Rio de Janeiro, 27/09/1061. p. 7. Disponível em: http://memoria.bn.br/docreader/386030/71030. Acesso em: 15 mai. 2019.

RIBEIRO, Amado. Professor Roberto Lyra e os Monstros da Central: crime contra a honra da pátria. Ultima Hora, Rio de Janeiro, 28/09/1061. p. 7. Disponível em: http://memoria.bn.br/docreader/386030/71044. Acesso em: 15 mai. 2019.

RIBEIRO, Amado. Polícia protege os matadores da Central: recusado promotor para crime de Monstros. Ultima Hora, Rio de Janeiro, 29/09/1061. p. 7. Disponível em: http://memoria.bn.br/docreader/386030/71058. Acesso em: 15 mai. 2019. 
RIBEIRO, Amado. "Parabelum" acusa os Chefes Amancio e Tenório: - "Eis aí os assassinos!". Ultima Hora, Rio de Janeiro, 30/09/1061. p. 7. Disponível em: http://memoria.bn.br/DocReader/386030/71070. Acesso em: 15 mai. 2019.

RIBEIRO, Amado. Estudantes e Operários Torturados Nas Jaulas da Polícia. Ultima Hora, Rio de Janeiro, 05/10/1961. p. 7. Disponível em: http://memoria.bn.br/docreader/386030/71132. Acesso em: 15 mai. 2019.

RIBEIRO, Amado. Celas de Cimento e Banhos Gelados Para os Presos Políticos do Coronel Ardovino. Ultima Hora, Rio de Janeiro, 06/10/1961. p. 7 . Disponível em: http://memoria.bn.br/DocReader/386030/71146. Acesso em: 15 mai. 2019.

RIBEIRO, Amado. Estudante Revela: “Cuspiram-me no Rosto e Rasgaram a Minha Roupa!". Ultima Hora, Rio de Janeiro, 07/10/1961. p. 7. Disponível em: http://memoria.bn.br/docreader/386030/71162. Acesso em: 15 mai. 2019.

RIBEIRO, Amado. Operários depõem: "Queriam fuzilar os presos políticos". Ultima Hora, Rio de Janeiro, 09/10/1961. p. 8. Disponível em: http://memoria.bn.br/docreader/386030/71175. Acesso em: 15 mai. 2019.

RIBEIRO, Amado. ROMITA: "Fiquei sabendo como é a polícia do governador!". Ultima Hora, Rio de Janeiro, 10/10/1961. p. 7. Disponível em: http://memoria.bn.br/docreader/386030/71196. Acesso em: 15 mai. 2019.

ÚLTIMA HORA. Proprietários de Jornais Dirigem-se ao Governador: Censura. Ultima Hora, Rio de Janeiro, 29/08/1961. p. 5. Disponível em: http://memoria.bn.br/docreader/386030/70674. Acesso em: 01 jun. 2019.

ÚLTIMA HORA. Cêrco e Violência Armada Para Silenciar 'Ultima Hora'. Ultima Hora, Rio de Janeiro, 01/09/1961. p. 1. Disponível em: http://memoria.bn.br/docreader/386030/70714. Acesso em: 02 jun. 2019.

\section{Referências}

ANTONIO, Mariana Dias. O sensacionalismo no jornal Ultima Hora-RJ: Sinais e ícones do Esquadrão da Morte (1968-1969). 2017. 268p. Dissertação (Mestrado em História), Setor de Ciências Humanas, Universidade Federal do Paraná, Curitiba, 2017.

ARGOLO, José Amaral. As luminárias do medo: vida, paixão e morte do jornalismo policial no eixo Rio de Janeiro-São Paulo. Rio de Janeiro: E-papers, 2008.

BARBOSA, Marialva. História Cultural da Imprensa: Brasil, 1900-2000. 2. ed. Rio de Janeiro: Mauad X, 2007.

BENEVIDES, Maria Victoria de Mesquita. O governo Jânio Quadros. 6. ed. 1. reimpr. São Paulo: Brasiliense, 1999.

BOURDIEU, Pierre. Sobre o Estado: Cursos no Collège de France (1989-1992). Trad. Rosa Freire d'Aguiar. São Paulo: Companhia das Letras, 2014.

CAMPOI, Isabela Candeloro. Adalgisa Nery e as questões políticas de seu tempo (1905-1980). 2008. 269p. Tese (Doutorado em História), Universidade Federal Fluminense, Instituto de Ciências Humanas e Filosofia, Niterói, 2008.

CHAGAS, Carlos. A ditadura militar e os golpes dentro do golpe. Rio de Janeiro: Record, 2014.

DULLES, John W. F. Carlos Lacerda. A vida de um lutador. Trad. Daphne F. Rodger. Rio de Janeiro: Nova Fronteira, 2000. v. 2. 
FAUSTO, Boris. História do Brasil. 13. ed. 2. reimpr. São Paulo: Editora da Universidade de São Paulo, 2010.

GÓMEZ, José María. (coord.). Políticas Públicas de Memória para o Estado do Rio de Janeiro: pesquisas e ferramentas para a não-repetição. Relatório de Pesquisa para a Comissão Estadual da Verdade do Rio de Janeiro, ago. 2015. Disponível em: http://doi.org/10.13140/RG.2.2.36713.44648. Acesso em: 25 abr. 2020.

LABAKI, Amir. 1961: a crise da renúncia e a solução parlamentarista. São Paulo: Brasiliense, 1986.

LAURENZA, Ana Maria de Abreu. Lacerda x Wainer: O Corvo e o Bessarabiano. 2. ed. São Paulo: Editora Senac, 1998.

LE GOFF, Jacques. História e Memória. vários tradutores. 5. ed. 2. reimpr. Campinas: Editora da Unicamp, 2006.

LEITÃO, Alexandre Enrique. O Esquadrão da Morte na Imprensa Carioca: a construção narrativa da experiência social e a legitimação da violência policial. 2017. 174p. Dissertação (Mestrado em Comunicação), Escola de Comunicação, Universidade Federal do Rio de Janeiro, Rio de Janeiro, 2017.

MCCOMBS, Maxwell. A Teoria da Agenda: a mídia e a opinião pública. Trad. Jacques A. Wainberg. Petrópolis: Vozes, 2009.

MEDEIROS, Benicio. A rotativa parou! Os últimos dias da Ultima Hora de Samuel Wainer. Rio de Janeiro: Civilização Brasileira, 2009.

MELLO E SOUZA, Cláudio; COELHO, Eduardo (orgs.). Carlos Lacerda / cartas 1933-1976. Rio de Janeiro: Bem-Te-Vi, 2014.

MELLO NETO, David Maciel. "Esquadrão da Morte": genealogia de uma categoria da violência urbana no Rio de Janeiro (1957 - 1987). 2014. 175p. Dissertação (Mestrado em Sociologia e Antropologia), Instituto de Filosofia e Ciências Sociais, Universidade Federal do Rio de Janeiro, Rio de Janeiro, 2014.

MENDONÇA, Marina Gusmão de. O demolidor de presidentes. 2. ed. Códex: São Paulo, 2002.

MISSE, Michel. Malandros, marginais e vagabundos e a acumulação social da violência no Rio de Janeiro. 1999. 413p. Tese (Doutorado em Ciências Humanas: Sociologia), Instituto Universitário de Pesquisas do Rio de Janeiro, Rio de Janeiro, 1999.

OLIVEIRA, Frederico Cícero Pereira de. Uma História do "Esquadrão da Morte": Mitos, Símbolos, Indícios e Violência no Rio de Janeiro (1957-1969). 2016. 173p. Dissertação (Mestrado em História), Faculdade de Formação de Professores, Universidade do Estado do Rio de Janeiro, São Gonçalo, 2016

RIBEIRO, Octavio. Barra Pesada. São Paulo: Círculo do Livro, [s.d.].

ROSE, R. S. Uma das coisas esquecidas: Getúlio Vargas e controle social no Brasil - 1930-1954. Trad. Anna Olga de Barros Barreto. São Paulo: Companhia das Letras, 2001.

SANTOS, Myrian Sepúlveda. Quatro histórias, duas colônias, uma ilha. Rio de Janeiro: Garamond, 2018.

SANDER, Roberto. O crime que abalou a República: violência, conspiração e impunidade no crepúsculo da Era Vargas. Rio de Janeiro: Maquinária, 2010.

SAPOLSKY, Robert M.. Behave: the biology of humans at our best and worst. Nova lorque: Penguin 
Press, 2017.

TELES, Janaína de Almeida. Ditadura e repressão no Brasil e na Argentina: paralelos e distinções (Apresentação). In: CALVEIRO, Pilar. Poder e desaparecimento: os campos de concentração na Argentina. Trad. Fernando Correa Prado. São Paulo: Boitempo, 2013. p. 7-18.

VARIKAS, Eleni. A escória do mundo: figuras do pária. Trad. Nair Fonseca \& João Alexandre Peschanski. São Paulo: Editora Unesp, 2014.

WAINER, Samuel. Minha razão de viver: memórias de um repórter. 11. ed. Rio de Janeiro: Record, 1988.

ZAFFARONI, Eugenio Raúl. O inimigo no direito penal. Trad. Sérgio Lamarão. 3. ed. 3. reimpr. Rio de Janeiro: Revan, 2015.

\section{Nota de autoria}

Mariana Dias Antonio é doutoranda em História pela Universidade Federal do Paraná e membro dos grupos de pesquisa "Cultura e Poder" e "Núcleo de Estudos Mediterrânicos - NEMED". Possui Licenciatura em História pelo Centro Universitário de Araras "Dr. Edmundo Ulson" (2011) e mestrado em História pela Universidade Federal do Paraná (2017). E-mail: mariana.diasant@gmail.com.

\section{Como citar esse artigo de acordo com as normas da revista}

ANTONIO, Mariana Dias. Os cárceres da Guanabara através do jornal Ultima Hora (1960-1961). Sæculum - Revista de História, v. 25, n. 43, p. 343-360, 2020.

\section{Contribuição de autoria}

Não se aplica

\section{Financiamento}

O presente trabalho foi realizado com apoio da Coordenação de Aperfeiçoamento de Pessoal de Nível Superior - Brasil (CAPES) - Código de Financiamento 001.

\section{Consentimento de uso de imagem}

Não se aplica

\section{Aprovação de comitê de ética em pesquisa}

Não se aplica

\section{Licença de uso}

Este artigo está licenciado sob a Licença Creative Commons CC-BY. Com essa licença você pode compartilhar, adaptar, criar para qualquer fim, desde que atribua a autoria da obra.

\section{Histórico}

Recebido em 16/05/2020.

Aprovado em 28/09/2020. 